Even students of considerable advancement in mechanics might do well to read this little book for the sake of the perspective which they might thus acquire.

Dr. Routh's treatises upon the various branches of mechanics, statics, dynamics of a particle, stability of motion, and in particular rigid dynamics, are so well known as to need no notice. It is therefore not surprising that Teubner, who is ever ready to publish a German translation of the best scientific literature of all nations, should now print this edition of Dr. Routh's Rigid Dynamics. As Professor Klein points out in his preface, this work is wholly different from any which has previously been available in German. To teach mechanics even in the most advanced portions from the standpoint of solving problems is furthest from the German method. We remember one instance in which a German reviewer recently said of a work under review that it was remarkable for its numerous examples. A count showed not more than forty in about five hundred pages of text. How Dr. Routh's work impresses this reviewer may be difficult to imagine. These English books are, however, an extreme. Placing such emphasis on the solution of problems is a result of the system of examinations at the colleges. The student is too apt to lose his perspective and to forget what the theory of mechanics is. In this the Germans are far ahead. We daresay that our English publishers would render no less service to our own scientific literature by translating the best German presentations of mechanics into English than Teubner has now rendered to German scientific literature by his translation of Dr. Routh's classic treatise on rigid dynamics.

YALE UNIVERSITY,

Edwin Bidwell Wilson. March 30, 1902.

\title{
THE GALOIS THEORY IN BURNSIDE AND PANTON'S THEORY OF EQUATIONS.
}

ONE of the most welcome additions to Burnside and Panton's "Theory of Equations" is the appearance in the new edition (the fourth) of a chapter devoted to the theory of substitutions and the theory of equations from the Galois standpoint. The British interest in the methods of Galois never has been very deep and about all the national literature is comprised in the last two pages of Cayley's article "Equation" in the Encyclopedia Britannica and four or 
five of his shortest papers, together with a few memoirs on special topics by other writers (as $e . g .$, Kirkman), while the present work is the first orderly presentation of the subject that has been undertaken by British mathematicians.

The authors begin with a discussion-modelled after Serret-of the general properties of substitutions and of multivalued functions. Everything is clearly and accurately written, and the authors are successful in the difficult task of making this rather dry subject interesting reading. The successive concepts are introduced in a natural manner, and the wording of both theorems and definitions is exact and careful. The numerous examples will supply a much-felt need in enabling the student to obtain a good foothold in the fundamentals of the theory.

When these preliminary developments have been completed, the group of an equation is defined and its existence established. Here, however, the treatment becomes open to serious criticism. For the all-important distinction between the formal and the numerical invariance of a function is disregarded and this omission weakens and vitiates the whole presentation. The matter is sufficiently familiar. Two formally distinct values of a function of the roots of a given equation may be numerically equal, and then the discriminant of the resolvent equation vanishes. This renders impossible the formation of the group, as defined by Burnside and Panton, and other methods must be adopted. The oversight is rather surprising, moreover, since nearly every writer on the subject (including Galois, Jordan, and Serret) is careful to say " numerical value" when speaking of the group-I believe the only exceptions are Netto, Hagen, and Pascal. The error in the "Repertorio" of the latter is corrected by Schepp in his German version of the book, while on this point Netto's treatise has undergone a more thorough and almost microscopically exhaustive series of reviews than falls to the lot of most mathematical productions. In fact Vogt, in his seventh chapter, goes to the trouble of re-proving the formal invariance theorems again de novo for numerical invariance, even committing the opposite error of stating that a group is formed by all the substitutions that leave a function numerically invariant. Of the same kind is a misstatement on page 246 of Burnside and Panton's work, where the coefficients of the Galois function are taken (following Netto) as " distinct arbitrary constants." Inasmuch as there is an infinite series of values that these coefficients cannot assume, the word " arbitrary" should be omitted ; Kronecker's "distinct indeterminates" are something quite different. 
The relation between the group and the equation is illustrated by the elementary equations as examples, and the irresolvability of the general equation is then discussed by Wantzel's (or Ruffini's $*$ ) method, slightly modified and simplified from Vogt's form. But inasmuch as Burnside and Panton have already introduced the group of the equation, it would have been preferable to use a more modern proof, resting on the properties of that group. By this method a somewhat tedious analysis is avoided, and the important connection between the group and the domain of rationality is exhibited. As the discussion stands few students are likely to appreciate this connection.

The brevity of the chapter and the consequent exclusion of many immediately connected topics of great interest is a matter of regret. Among the chief of these topics are the distinction between simple and composite groups (barely referred to on page 244), the question of primitivity and imprimitivity, the general theory of resolvents, and the properties of abelian equations (uniserial abelians are treated in an appendix). A word or two on Galoisian equations and the general solvable equations would not have been amiss. Personally I think it would have been better to have omitted certain details in other parts of the book in order to make room for a more complete treatment here-supposing that the authors did not care to undertake such a radical change as the early introduction and the systematic employment of the Galois principles, advantageous though the change would have been.

One last criticism. The references given-Serret, Jordan, Netto and Vogt-are not very complete. Weber's "Lehrbuch der Algebra,"' which is past question the most important work on the subject, is not mentioned. Hölder's very valuable monograph in the Encyclopädie der mathematischen Wissenschaften, Netto's Algebra, and Bianchi's "Lezioni sulla teoria dei gruppi di sostituzioni" certainly should be also included. The omission of Echegaray's "Lecciones sobre la resolución de las ecuaciones" is more pardonable, and the reprint of Pierpont's articles from the Annals of Mathematics was probably of too recent a date to have attracted the attention of the writers.

University of Pennsyluania,

Burton Scott Easton. April 3, 1902.

* Wantzel's paper in Vol. 4 of the first series of the Nouvelles Annales de Mathématiques (1845) is the source to which this proof is commonly referred, but substantially the same was given by Ruffini in 1813 in his book " Reflessioni intorno alla soluzione dell'equazioni algebraiche." 